\title{
Meningioma in pregnancy: a rare case report
}

\section{Raji Chinniah*, Kalarani Ethirajan, Jeyarani Pitchiah, Rubini Mariappan}

Department of Obstetrics \& Gynaecology, Government Thanjavur Medical College, Thanjavur, Tamilnadu, India

Received: 18 February 2016

Revised: 14 March 2016

Accepted: 15 March 2016

\section{*Correspondence:}

Dr. Raji Chinniah,

E-mail: rajidr_2003@yahoo.co.in

Copyright: () the author(s), publisher and licensee Medip Academy. This is an open-access article distributed under the terms of the Creative Commons Attribution Non-Commercial License, which permits unrestricted non-commercial use, distribution, and reproduction in any medium, provided the original work is properly cited.

\begin{abstract}
Central nervous system tumor in pregnancy is rare. We report a case of such a tumor diagnosed in the third trimester of pregnancy. Patient presented with signs of increased intracranial tension and MRI showed a meningioma. Caesarean section along with craniotomy and tumor excision done successfully in the same sitting. Mother and the baby recovered well.
\end{abstract}

Keywords: Pregnancy, Meningioma, CNS tumors

\section{INTRODUCTION}

Intracranial tumors in pregnancy are very rare but serious and life threatening. ${ }^{1}$ Incidence in pregnancy is same as in nonpregnant individuals. Neurological symptoms first appearing during pregnancy must be distinguished from pregnancy complications. Primary CNS tumors incidence is less than 6 per $1,00,000$ females. Asymptomatic patients will become symptomatic and symptomatic patients will have exacerbation of symptoms during pregnancy. We report here a case of meningioma diagnosed in the third trimester in an otherwise healthy pregnant mother. Caesarean section followed by craniotomy and excision of tumor was done successfully in same sitting.

\section{CASE REPORT}

Mrs R, a 23yr old $\mathrm{G}_{3} \mathrm{P}_{2} \mathrm{~L}_{1}$, with previous two normal deliveries, first stillborn, second live baby, now at 37 weeks of gestation admitted with headache, projectile vomiting and multiple episodes of loss of consciousness of one week duration. First and second trimesters were uneventful. There was no other significant past, personal or family history.
Physical examination showed a Glasgow Coma Scale (GCS) score of 15. Patient was not anemic, afebrile, PR: 68/min., BP: 100/60 mm of $\mathrm{Hg}$. Cardiovascular and respiratory system were normal. On abdominal examination, uterine size corresponded to 34 weeks gestation, fetus in cephalic presentation with a normal heart rate.

Basic blood and urine investigations were normal. Obstetric USG showed a single live fetus, cephalic, 34 weeks gestation with an AFI of $7 \mathrm{~cm}$. MRI Brain showed right parieto-occipital meningioma adherent to cup of sagittal sinus with mass effect and midline shift (Figure 1).

As per neurologist's opinion patient was treated with steroids and anticonvulsants. Non stress test was reactive. Patient was kept under observation.

Three days later, patient developed features of coning. Hence taken up for emergency caesarean section under general anaesthesia. An alive female baby of $2.4 \mathrm{~kg}$ was delivered with a good Apgar. In the same sitting, right parieto-occipital parasagittal craniotomy with total excision of tumor was done by the neurosurgical team. Intraoperatively patient was transfused with 3 units of 
blood and 3 units of fresh frozen plasma. Postoperative period was uneventful.

Mother and baby were discharged in good condition with the advice to continue antiepileptic (Figure 2, 3).

\section{Biopsy report}

- Cytokeratin-strongly positive.

- Vimentin positive.

- Progesterone receptor positive

- Estrogen receptor and Glial Fibrillary Acidic Protein -Negative Immunohistochemistry (IHC) confirmed the diagnosis of secretory meningioma.

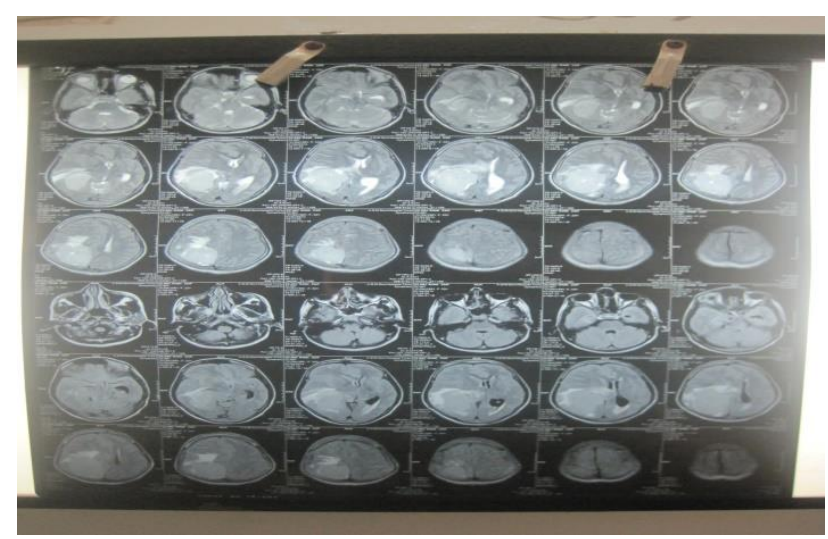

Figure 1: Preoperative MRI brain.

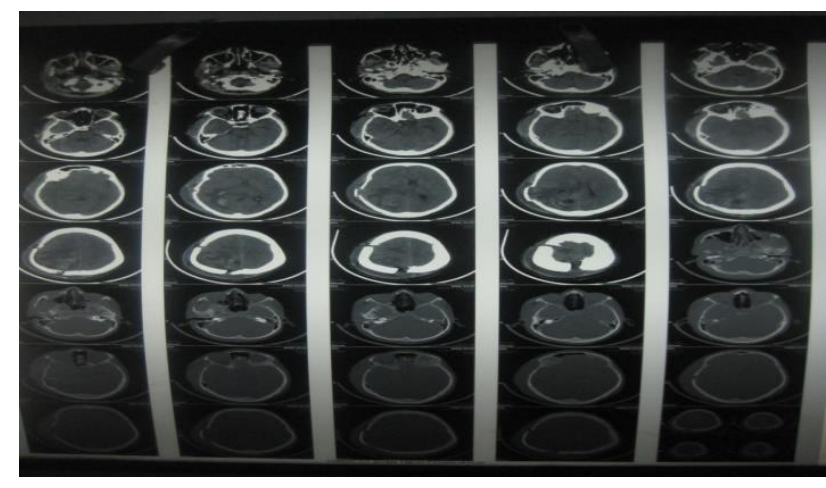

Figure 2: Post-operative MRI Brain.

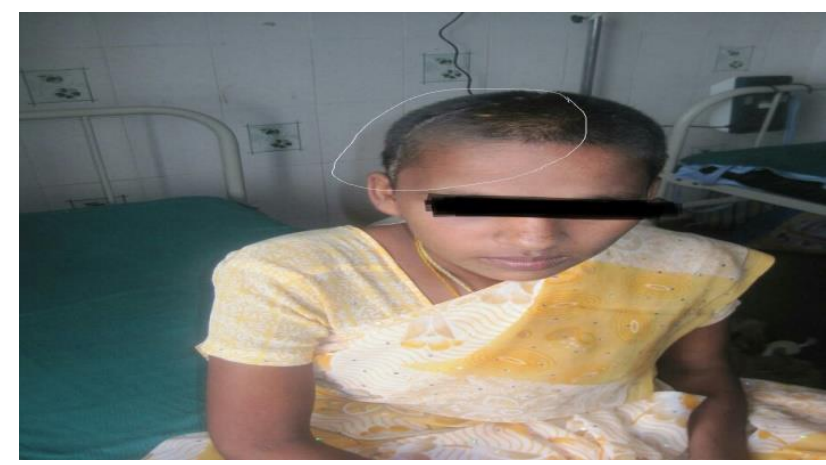

Figure 3: Post-operative picture of the patient.

\section{DISCUSSION}

Intracranial tumors during pregnancy were first described in $1898 .^{2}$ Glial neoplasms are the most common tumors followed by meningiomas and acoustic neuromas. ${ }^{3}$ Growth of meningioma accelerates during the second half of pregnancy. 4,5

Exacerbation of symptoms due to fast growth in pregnancy ${ }^{6}$ is mainly due to estrogen and progesteron receptors, increased vascularity, edema and pregnancy related immune tolerance. After delivery, regression of tumor size and resolution of symptoms have been described. $^{7-9}$

Local tumor effects are loss of function (focal deficit) and seizure. Herniation occurs due to mass of the tumor, hydrocephalus and cerebral edema. The clinical presentation of headache, vomiting and seizure can be misdiagnosed as hyperemesis gravidarum in early pregnancy and preeclampsia in late pregnancy. But abnormal fundoscopy, visual impairment, focal seizure and lateralizing neurological deficit support the diagnosis of intracranial mass lesion. So, confirmation with MRI should be done. The cautious use of CT with shielding of the uterus has been superseded by MRI because of its high sensitivity diagnostic index and no radiation effect.

Management of meningioma in pregnancy depends on clinical presentation. The management strategy for brain tumors during pregnancy should be tailored to the individual case. Advances in noninvasive fetal monitoring such as fetal biophysical profile and umbilical artery doppler velocimetry, and advances in neuroanesthesia and microsurgical techniques permit safe neurosurgical management of brain tumors during pregnancy. Pregnancy can be continued with fetal monitoring, close and regular clinical and neurological evaluation of the mother. Spontaneous vaginal delivery can be allowed. Caesarean delivery is indicated if there are any signs of increased intracranial pressure.

If surgery is planned during pregnancy, care should be taken to avoid intraoperative blood loss, hypotension, hypovolemia and hypoxia to prevent hazardous effects on fetal circulation. Steroids should be given to treat cerebral edema. The usual regimen is a divided dose of 2-4 mg dexamethasone every 6 hours, tapered slowly over a few days. Administration of mannitol should be cautious and reserved only for acute emergency because it crosses the placenta and affects the fetus. Seizures should be controlled preferably with monotherapy. Physicians should realize that the risks or complications of epilepsy are more serious than the side effects of anticonvulsants. Patients with seizures should be maintained on folic acid from early pregnancy and should receive supplemental vitamin $-\mathrm{K}_{1}$ three weeks before and during confinement to minimize the risk of drug induced neural tube defects or blood dyscrasias. 
Indications for urgent neurosurgical management includes malignancy, active hydrocephalus, benign tumor with signs of impending herniation or progressive neurological deficit. ${ }^{10}$ In our case, emergency caesarean along with craniotomy and total excision of the tumor was done due to herniation.

\section{CONCLUSION}

Meningioma diagnosed during pregnancy should be managed according to the severity of maternal neurological symptoms and gestational age of fetus.

Advances in neuroanesthesia and the neurosurgical armamentarium allow safe resection of brain tumors in pregnancy. A multidisciplinary approach involving a neurosurgeon, an obstetrician and an anaesthesiologist is required to improve maternal and fetal outcome.

Funding: No funding sources Conflict of interest: None declared

Ethical approval: Not required

\section{REFERENCES}

1. Stevenson CB, Thompson RC. The clinical management of intracranial neoplasms in pregnancy. Clinical Obstetrics and Gynecology. 2005;48(1):2437.

2. Bernard MH. Sarcome cerebral à evolution rapide au cours de la grossesse et pendant les suites des couches. Bulletin de la Society d'Obstetrique de Paris. 1898;1(1):296-8.

3. Roelvink NCA, Kamphorst W, Rao BR. Pregnancyrelated primary brain and spinal tumors. Archives of Neurology. 1987;44(2):209-15.

4. Carroll RS, Zhang J, Black PM. Expression of estrogen receptors alpha and beta in human meningiomas. Journal of Neuro-Oncology. 1999;42(2):109-16.

5. Gilroy J. Meningioma in Basic Neurology, McGrawHills, New York, NY, USA, 3rd edition, 2000.

6. Lusis EA, Scheithauer BW, Yachnis AT. Meningiomas in pregnancy: a clinicopathologic study of 17 cases. Neurosurgery. 2012;71(5):951-61.

7. Cahill DW, Bashirelahi N, Solomon LW. Estrogen and progesterone receptors in meningiomas. Journal of Neurosurgery. 1984;60(5):985-93.

8. Lesch KP, Fahlbusch R. Simultaneous estradiol and progesterone receptor analysis in meningiomas. Surgical Neurology. 1986;26(3):257-63.

9. Shitara S, Nitta N, Fukami T. Tuberculum sellae meningioma causing progressive visual impairment during pregnancy: case report. Neurologia MedicoChirurgica. 2012;52(8):607-11.

10. Wang LP, Paech MJ. Neuroanesthesia for the pregnant woman. Anesthesia \& Analgesia. 2008;107(1):193-200.

Cite this article as: Raji C, Kalarani E, Jeyarani P, Rubini M. Meningioma in pregnancy: a rare case report. Int J Reprod Contracept Obstet Gynecol 2016;5:1270-2. 